\title{
Transdiciplinary Research as the Peace Prospective for Community Based Village Tourism: An Example of Machhapuchhre Model Trek in Western Nepal
}

\author{
Pranil Kumar Upadhayaya ${ }^{1}$ \\ ${ }^{1}$ Department of Development Studies, Kathmandu University, Nepal
}

\begin{abstract}
Tourism is a composite multifaceted product-service with the overlapping roles of interdependent sub-sectors. The dual faces (various problems for causing conflict and potentials for building-peace) of tourism have compelled its actors to try for innovative models by crossing the disciplinary boundary. On this conceptual foundation of the structural reality, this paper presents the case study of a Machhapuchhre Model Trek (MMT), a community based tourism model situated in the northern part of Pokhara in Western Nepal. Going beyond disciplinary research, the MMT is developed on the basis of the transdiciplinary approach which has brought scientific researchers [e.g. PhD and senior researchers of Kathmandu University and the Swiss National Centre of Competence in Research (NCCR) North-South], tourism industry practitioners (e.g. trekking agencies in Pokhara), local communities (e.g. represented by seven villages in MMT area) and local government together for common aim and coordinated partnership actions. The transdisciplinary research process helps grasp lessons on triggering societal learning, appreciating differences, boosting concerted actions, mitigating syndromes of unsustainable development, lessening conflict, and thereby supporting to build peace. This paper adds knowledge on the potential value of transdisciplinary research on tourism.
\end{abstract}

\section{Introduction}

Research and cooperation are significant for the peace sensitive development of tourism. Tourism is the combination several composite sub-sectors and their independent actors with their differing interests and overlapping roles. These characteristics of tourism make it a complex, multifaceted, and a distinctive sector. The review of a number of literatures [1-3] reveals this characteristics and the lack of coordinated industry-wide actions in tourism. It often results with the conflict sensitiveness and peace-lessness of tourism. This scenario unquestionably demands for the multidisciplinary treatment of tourism [4]. In this premise, this paper argues that the integrated actions on a transdisciplinary research are inevitable for the peace sensitive development of tourism. The transdisciplinary approach of research allows both researchers and the researched communities for their mutual involvements for societal learning and concerted actions. 
Based on these specific characteristics of transdisciplinary approach of research as the conceptual framework (brief elaboration under the heading of transdisciplinary research) in the interdisciplinary theme of community based village tourism, this paper exemplifies a researchlinked and empirically executed case of Partnership Actions for Mitigating Syndromes (PAMS) (see end note 1) tourism project on Machhapuchhre Model Trek (MMT) in Western Nepal. MMT is a community based village tourism model route as situated towards the north from Pokhara on a distance of $12 \mathrm{~km}$ in Kaski district in Western development region of Nepal. PAMS tourism project in MMT route offered an empirical basis for research by applying the research findings to real situations. The transdisciplinary research through PAMS project is relevant in the sense that it is pioneer work of this type in context of tourism sector of Nepal which is covered in this paper.

\section{Methodology}

The PAMS tourism project titled 'Developing a community based tourism model in Kaski district in Western Nepal', is the main source of information for this article. This research project is the integral part of the $\mathrm{PhD}$ research of this author as conducted in field of 'tourism, conflict and peace' at Kathmandu University (KU) in association with the South Asia Regional Coordination Office of the Swiss National Centre of Competence in Research (NCCR) North-South (see end note 2) [5].

As a part of action research under PAMS project, a set of methods are utilized for the formation of this paper. These included review of literatures, semi-structure interviews, focus group discussions, organization of workshops (one each at local regional level and a national level) and some key actions on partnership basis among scientific researchers, tourism practitioners and local communities. The presentations and feedbacks in these workshops were also followed by talks and discussions on how tourism could promote peace and prosperity in Nepal. Various infrastructure and capacity building activities were held at MMT route. These activities aimed to trigger societal learning through both mutual interactions, debates, discussions and concerted actions [6].

\subsection{Transdisciplinary Research Approach}

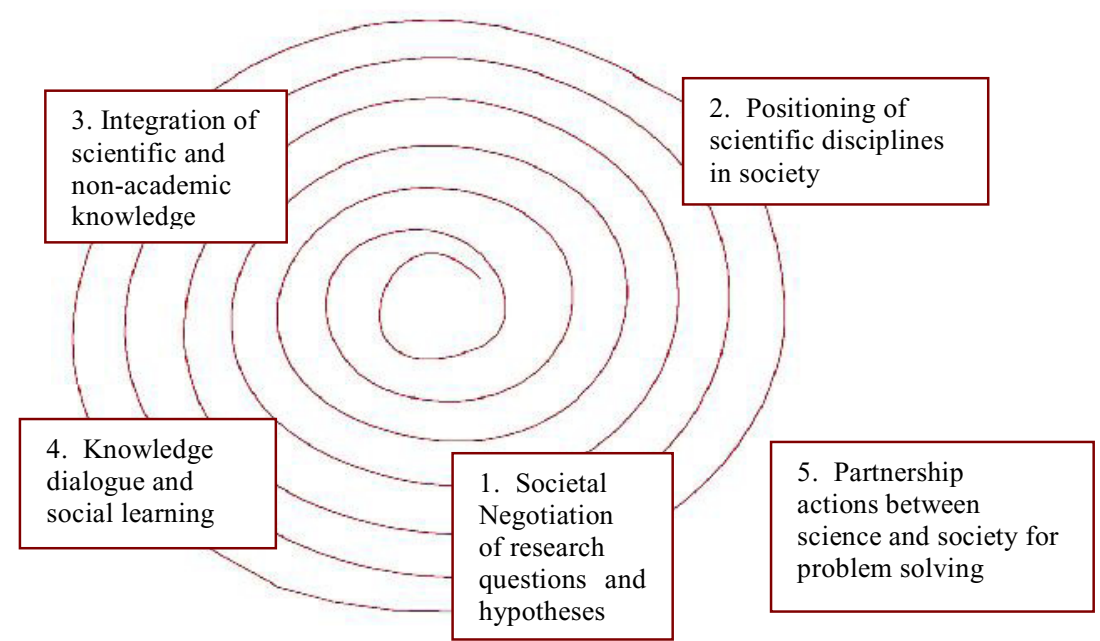

Figure 1. A conceptual framework for operationalising transdisciplinary approach in a research process

Source: Adapted from Herweg [8] 
Transdisciplinary research is conceptual framework that constitutes various stakeholders like researchers, practitioners; local communities etc. and emphasize the collaboration between science (scientific actors) and society (societal actors) for mutual learning and common goal [7]. A conceptual framework of transdisciplinary research clarifies the integration of various actors and elements in this research process.

Attributed with the capacity of triggering social learning process, this research process allows to position the disciplinary research experience within an inter and transdiciplinary team, working with site specific mix of social, economic and ecological issues.

\section{Peace-potential of Community Based Village Tourism in Nepal}

The Traditional culture and unspoiled culture are key assets for all kind of tourism in Nepal. These attractions offer Nepal with comparative advantage for the development of this sector. Tourism contributed $9.4 \%$ to Nepal's gross domestic product (GDP) with many other indirect and induced effects in 2012. On this premise, a number literature [9-10] reveal the great prospect of community based village tourism for prosperity and peace in Nepal. For it, Nepal's enormous village tourism prospect coinciding with trekking and homestay potentials are the most viable option for creating employments, generating income, preserving local environment, providing educational opportunities, increasing community's carrying capacity, and diversifying the economic benefits on village areas inhabited by 83 percent of village people [11].

Tourism for Rural Poverty Alleviation Programme, a community based tourism model based on appreciative participatory planning and action during the first half (2001-2005) of the first decade this century demonstrated it as a tool for alleviating poverty, engaging local bodies, strengthening environmental conservation, empowering disadvantaged groups and women, and social mobilization [12].

The policy revisits of the post-conflict government after the end of a decade (1996-2006) long armed conflict have two prime focuses in tourism sector: (a) decentralizing tourism and widening the participations of people in tourism in rural areas and (b) giving access to the benefits of tourism to rural communities. Such policy interventions emphasize the high role of community based village tourism for mitigating structural conflict and enhancing prosperity and peace (MoTCA, 2009; Sharma et al., 2010) [11,13]. Though some efforts done at few places like Annapurna Conservation area in 1990s, Ghalegaun (Lamjung district) in 1992 and Sirubari (Syanja district) in 1997 offer the instances of community based tourism models, but Nepal lacked the innovation and application of an approach which could allow and strengthen the partnership and collaboration of all key actors like scientists, tourism practitioners, local society, and local government in attaining the peace potential of community based village tourism.

\section{Transdiciplinary Research for Peace-building on Tourism: An Empirical Case of Machhapuchhre Model Trek}

The PAMS project was formulated with the objectives of constructing minimum preliminary infrastructures and buildings capacity of local people on homestay operation and trekking tourism. The field research works of the PhD research of this author under NCCR/KU had found the need of formulating conflict sensitive tourism guidelines on MMT for its peace sensitive development.

A conceptual framework (figure 2) illustrates the whole process of MMT for its development on the basis of transdisciplinary research approach. 


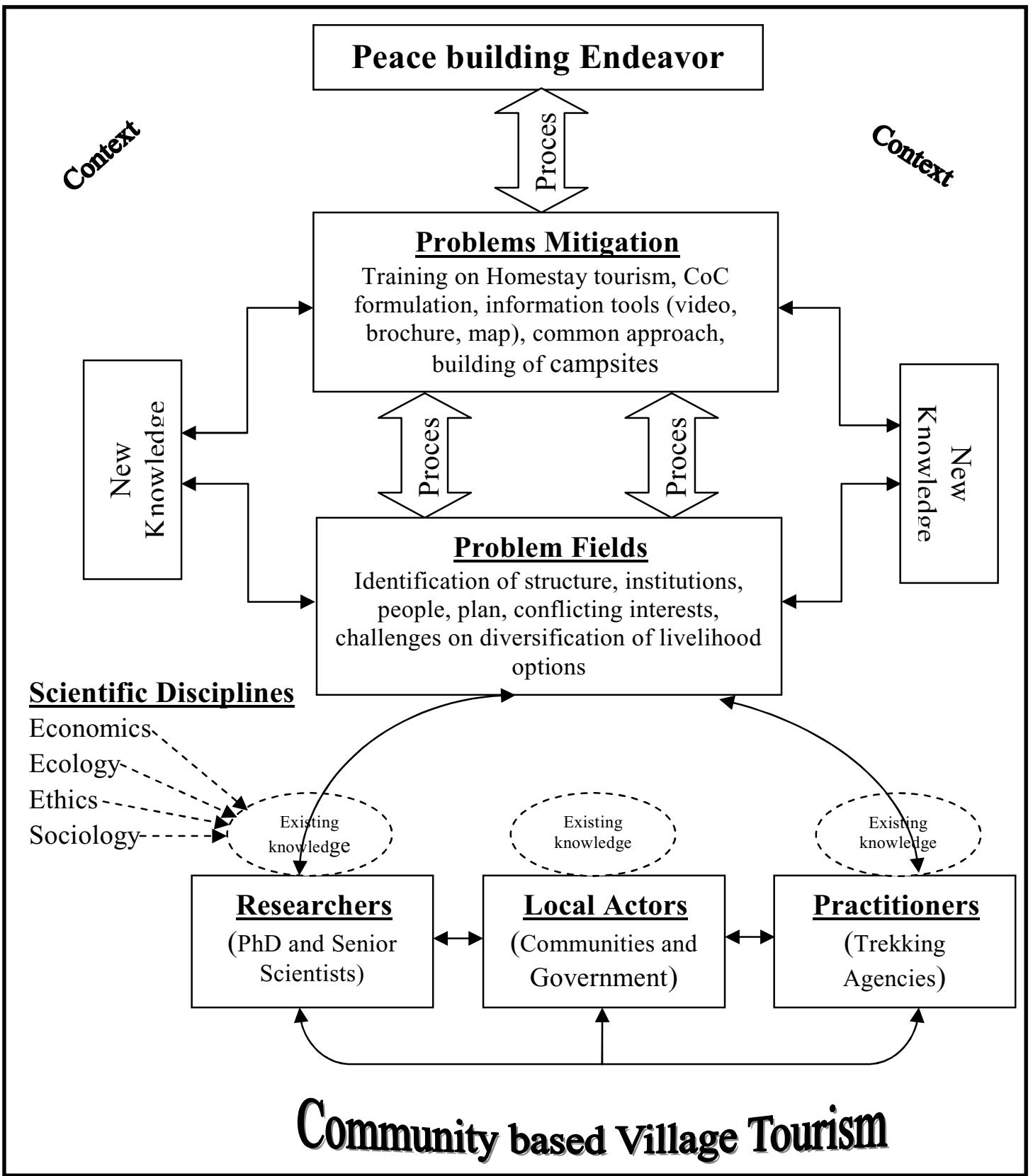

Figure 2. Conceptual framework with researchers-practitioners interaction model of transdisciplinarity on MMT

(Source: Developed by Author, 2013)

The PAMS tourism project brought scientific researchers [e.g. PhD researcher (as this author) and senior scientists of Kathmandu University and the South Asia Regional Office of the Swiss National Centre of Competence in Research (NCCR) North-South], tourism industry practitioners (e.g. 80 trekking agencies represented by Trekking Agencies' Association of Nepal-Western Regional Association), local governmental and community actors in identifying the problems and 
challenges of village tourism, determining strategies and applying actions on MMT (see figure 2). The project on MMT route aimed at triggering societal learning through concerted efforts. There are following outcomes of PAMS project which demonstrate the peace potential in the process (figure 2) of its development and execution on MMT route (Bechtel, 2010; TAAN WRC, 2010) [14-15].

\subsection{Applied with bottom-up participatory planning process}

4.2 Emerged with a number of following outputs through concerted actions between researchers, local communities, and trekking tourism practitioners

- Completion of five camp sites, five porter shelters, and twenty five trail marking boards.

- Delivery of basic trainings to ninety five women trainees of seven villages in MMT route on homestay tourism operation.

- Preparation of Machhapuchhre Model Trek route map

- Production of a video documentary titled 'Peace through Tourism'

4.3 Formulated and applied with peace-sensitive codes of conduct (Responsible Tourism Guidelines)

4.4 Appeared with mutual societal learning through transdisciplinary approach

4.5 Benefited to multiple actors through partnership actions

4.6 Framed with sustainable and inclusive institutional structure

4.7 Resulted with a complete village tourism product

This village tourism in this route appears in two forms. One is as an organized trekking route and the other is the homestay provisions for tourists in the local people's houses in seven villages namely Lahachowk, Ghachowk, Machhapuchhre, Rivan, Lwangghale, Sardikhola, and Dhital (TAAN WRC, 2010) [14]. An average of 3000 international trekking tourists has been visiting in and around MMR area per year since 2010 (Thapaliya et al., 2012) [15]. There are around six to eight Home-stays in all villages. Home-stay business has played a major role in empowering some women by making them economically independent. They are making money and that is improving their standard of living. The households who run 10 home-stay earn an average of Nepalese Rupees 27, 000 a year depending upon the number of rooms available in their home (Personal communication with Him Kumari Gurung, President of home-stay operators committee in Lwang on 30 April 2014)

\section{Conclusion}

Community based village tourism has gained high attention due to it interconnection with peacebuilding. The purpose of this paper was to explore the potential of transdisciplinary research for building peace on community based village tourism on MMT.

A framework was utilized to know the conceptual foundation coinciding with step by step systematic process of transdisciplinary research in cooperation between scientific and non-academic actors. Another conceptual framework of trandiscipinary research in researchers-practitioners interaction model was applied in local context in Machhapuchhre Model Trek region to identify the context, actors, problems, process, various strategies, and practical contributions of transdisciplinary research. It was found that the partnership actions facilitated by this mode of research gave prospect 
to apply and test the role of tourism for prosperity and peace. The practical aspects provided opportunities to the researchers ( $\mathrm{PhD}$ and senior scientists) to link tourism for prosperity and peace. The transdisciplinary research approach enabled researchers to bridge the gap between research and society.

The lessons learned from the collaborative involvement of this small scale partnership approach are to be seen just as the beginning in this process. The overwhelming expansion of the partnerships between researchers (as science) and society (as the real local communities) in community based rural tourism on transdisciplinary approach are high necessities in future for which the continuity of such transdisciplinary research programs in different modes at local and regional levels can be momentous.

\section{End Notes}

\section{PAMS}

PAMS are small participatory projects of limited time and financial scope carried out over a fixed time period between 1 to 1.5 years by local actors in partnership with scientific and non- scientific stakeholders under the framework of the Swiss National Centre of Competence in Research (NCCR North-South). Transdisciplinarity, social learning and syndromes mitigation are three prime program goals of PAMS. Transdisciplinarity is fostered under PAMS by the exchange of knowledge, views, skills and social learning between science and society (Haupt et al., 2006) [15].

\section{NCCR North-South}

The Swiss National Centre of Competence in Research (NCCR North-South) is one of 27 National Centres of Competence in Research established for research partnerships for mitigating syndromes of global change by the Swiss National Science Foundation. The NCCR North-South carried out disciplinary, interdisciplinary and transdisciplinary research on issues relating to sustainable development in developing and transition countries as well as in Switzerland.

\section{References}

1. O.Moufakkir and I.Kelly, Eds. 2010, Tourism, Progress and Peace, Wallingford: CAB international (2010)

2. P.K.Upadhayaya, P.K. Post-conflict tourism in Nepal: Challenges and opportunities for preventing latent conflict, The Gaze Journal of Tourism and Hospitality 1, 1: 28-42 (2009)

3. P.K.Upadhayaya, 2011. Peace through Tourism. A Critical Look in Nepalese Tourism, Nepal Tourism \& Development Review 1, 1: 15-40. Accessed from Nepal Journals Online website http://www.nepjol.info/index.php/NTDR/article/view/7368 on 5 August 2014.

4. R.R.Kunwar. Tourists and tourism: Science and industry interface, Kathmandu: Ganga Sen Kunwar (2010)

5. D.Bechtel, 2010, Nepal could reap Swiss tourism harvest. Retrieved from Swiss Broadcasting Corporation's website http://www.swissinfo.ch/eng/culture/Nepal_could_reap_Swiss_tourism_harvest.html?cid=853165 4 on 28 July 2014.

6. NCCR North-South, 2011, Research Theme on Developing a community based tourism model in Kaski district in Western Nepal (SAS-2_05), Retrieved from NCCR North-South website http://www.nccr-north-south.unibe.ch/project/project.asp on 14 April 2014.

7. H.Hurni, U.Wiesmann and R.Schertenleib, Eds. 2004, Research for Mitigating syndromes of Global Change. A Transdisciplinary Appraisal of Selected Regions of the World to Prepare 
Development-Oriented Research Partnerships. Perspectives of the Swiss National Centre of Competence in Research (NCCR) North-South, University of Berne, Bern: Geographica Bernensia 1, (2004)

8. K.Herweg, 2011, Coping with global change and striving for sustainable development. The interand transdisciplinary research approach. A presentation made at NCCR North-South Asia Regional Training Course on 1 July 2011 in Kathmandu, Nepal (2011)

9. S.B.Pradhananga, Village: The new tourist destination of Nepal, New Delhi:

10. S.R.Sharma, Upreti, B.R. and Upadhayaya, P.K., 2010, Community-based and peace-sensitive tourism: fulfilling Nepal's potential. Evidence for Policy Series, Regional edition South Asia, No. 3. Accessed from the Swiss National Centre of Competence in Research (NCCR) North-South website http://www.north-south.unibe.ch on 28 April 2014.

11. MoTCA, Paryatan Niti 2065 (Tourism Policy 2009), Kathmandu: Ministry of Tourism and Civil Aviation (MoTCA) (2009

12. D.P.Dhakal, (2005). Policy Paper 4 on Sustainable Rural Tourism for Improved Livelihood of Local Communities. Kathmandu: Economic Policy Network, Ministry of Finance and Asian Development Bank (2005)

13. TAAN WRC, 2010, Final report on developing a community based tourism model in Kaski district in Western Nepal (Publication No. PAMS No. SAS-2_05), Kathmandu: Trekking Agencies Association of Nepal (TAAN) Western Regional Chapter (WRC). Accessed from the Swiss National Centre of Competence in Research (NCCR) North-South website http://www.nccr-north-south.unibe.ch/project/project.asp on 25 June 2014

14. M.Thapaliya, G.S.Rai, A.Shrestha, and O.Pande, 2012, Home-stay: Assessment in Lwang Ghalel, Nepal Tourism and Development Review 2, 1: 105-140, Accessed from Kathmandu University website http://www.ku.edu.np/ntdr/index.php?go=vol2no1 on 5 August 2014.

15. F.Haupt, F.Pfister, F.Bachmann, P. Messerli, U.Wiesmann,2006, Bridging "Global" and "Local" Knowledge for Added Value in Mitigation Research. Experience from Partnership Actions for Mitigating Syndromes (PAMS) in the NCCR North-South. Internal Report of the NCCR North-South, Bern: NCCR North-South (2006) 